\title{
Assessment of atrial septal defects in adults comparing cardiovascular magnetic resonance with transoesophageal echocardiography
}

Karen SL Teo*, Patrick J Disney, Benjamin K Dundon, Matthew I Worthley, Michael A Brown, Prashanthan Sanders and Stephen G Worthley

\begin{abstract}
Background: Many adult patients with secundum-type atrial septal defects (ASDs) are able to have these defects fixed percutaneously. Traditionally, this has involved an assessment of ASD size, geometry and atrial septal margins by transoesophageal echocardiography (TOE) prior to percutaneous closure. This is a semi-invasive technique, and all of the information obtained could potentially be obtained by non-invasive cardiovascular magnetic resonance (CMR). We compared the assessment of ASDs in consecutive patients being considered for percutaneous ASD closure using CMR and TOE.

Methods: Consecutive patients with ASDs diagnosed on transthoracic echocardiography (TTE) were invited to undergo both CMR and TOE. Assessment of atrial septal margins, maximal and minimal defect dimensions was performed with both techniques. Analyses between CMR and TOE were made using simple linear regression and Bland Altman Analyses.

Results: Total CMR scan time was 20 minutes, and comparable to the TOE examination time. A total of 20 patients (M:F $=5: 15$, mean age 42.8 years \pm 15.7$)$ were included in the analyses. There was an excellent agreement between CMR and TOE for estimation of maximum defect size $(R=0.87)$. The anterior inferior, anterior superior and posterior inferior margins could be assessed in all patients with CMR. The posterior superior margin could not be assessed in only one patient. Furthermore, in 1 patient in whom TOE was unable to be performed, CMR was used to successfully direct percutaneous ASD closure.
\end{abstract}

Conclusions: CMR agrees with TOE assessment of ASDs in the work-up for percutaneous closure. Potentially CMR could be used instead of TOE for this purpose.

\section{Background}

Atrial septal defects are the most common congenital cardiac malformation first diagnosed in adults and account for approximately $10 \%$ of all congenital heart lesions [1]. Patients with a significant shunt $(\mathrm{Qp} / \mathrm{Qs}>1.5 /$ 1.0) experience symptoms over time with effort dyspnoea seen in about $30 \%$ of patients by the third decade and in over $75 \%$ of patients by the $5^{\text {th }}$ decade. Complications may include the development of pulmonary hypertension, supraventricular arrhythmias (atrial fibrillation and

* Correspondence: karen.teo@adelaide.edu.au

${ }^{1}$ Cardiovascular Research Centre, Royal Adelaide Hospital and The University of Adelaide, Adelaide, South Australia

Full list of author information is available at the end of the article atrial flutter) and right-sided heart failure from right ventricular volume overload.

Surgical closure of atrial septal defects (ASDs) has previously been shown to have excellent results in both medium and long term studies [2], but is associated with significant morbidity and mortality [3]. Many adults with secundum ASDs are now able to have these defects closed percutaneously using septal occluder devices such as the Amplatzer Septal Occluder (ASO), a self-expanding circular double disc with a conjoint waist containing polytetrafluoroethylene (PTFE) and a nitinol mesh. This device has now become an accepted alternative to surgical repair with studies comparing ASO device closure to

() 2010 Teo et al; licensee BioMed Central Ltd. This is an Open Access article distributed under the terms of the Creative Commons AtBHoWed Central tribution License (http://creativecommons.org/licenses/by/2.0), which permits unrestricted use, distribution, and reproduction in any medium, provided the original work is properly cited. 
surgical closure showing decreased complication rates, shorter hospital stays and greater cost-effectiveness [4].

The echocardiographic morphology of the ASD and accurate assessment of the stretched diameter has been important for patient selection. Initially, it was felt that atrial septal defects up to $26 \mathrm{~mm}$ stretched balloon diameter could be closed with the ASO [5]. More recently, there is registry data of larger ASDs closed successfully using the $40 \mathrm{~mm}$ ASO [6]. Inclusion criteria for percutaneous ASD closure have included: 1) the presence of a secundum ASD $<40 \mathrm{~mm}$ by echocardiography, 2) a leftto-right shunt with a Qp/Qs ratio of $>1.5: 1$ or the presence of right ventricular volume overload 3) patients with minimal shunt in the presence of symptoms and 4) the presence of a distance of $>5 \mathrm{~mm}$ from the margins of the ASD to the coronary sinus, atrioventricular valves and right upper pulmonary vein as measured by echocardiography [7-9]. Traditionally, these assessments of ASD size, geometry and atrial septal margins have been obtained by transoesophageal echocardiography (TOE) prior to the percutaneous closure $[7,10]$. This is a semi-invasive technique and all of the information could potentially be obtained by non-invasive cardiovascular magnetic resonance (CMR). Furthermore, TOE is imperfect at assessing all atrial septal margins. A large atrial septal defect that is located inferoposteriorly is difficult to both assess and close [7] and relates to the limited assessment of the posterior inferior margin by TOE [11]. Although 3-D TOE may improve this, this new technology is not yet widely available, and yet to be shown to be superior to 2D TOE for this purpose.

The aim of this study was to compare the assessment of atrial septal defects in consecutive adult patients being considered for percutaneous ASD closure using CMR and TOE.

\section{Methods \\ Subjects}

Consecutive patients with secundum atrial septal defects diagnosed on transthoracic echocardiography (TTE) were invited to undergo both transoesophageal echocardiography (TOE) and CMR.

\section{Transoesophageal echocardiographic imaging}

TOE was performed with a Sonos 5500 (Phillips) TOE system with a multiplanar $7.0 \mathrm{mHz}$ phased-array transducer. Cross-sectional studies of the atrial septum were performed utilising multi-plane views as previously described: mid-oesophageal 4-chamber views, short axis view and biatrial long axis views [7].

\section{Cardiovascular Magnetic Resonance}

CMR studies were performed with subjects in the supine position using a 1.5 Tesla scanner (Siemens Sonata, Ger- many) and a phased array surface coil. Images were obtained during end-expiratory breath-hold (8 to $10 \mathrm{sec}-$ onds) with retrospectively cardiac-gated True FISP (Fast imaging with steady-state free precession) sequences. Both short (modified bi-atrial) and long axis images (4 chamber views) were obtained through the ASD, with section thickness of $6 \mathrm{~mm}$ and no intersection gap. Thus, consecutive slices were obtained to cover the whole of the interatrial septum in both short and long axis views. Assessment of atrial septal margins, maximal and minimal defect dimensions in both short and long axis views was performed.

\section{Measurement of atrial septal margins and defect size}

TOE and CMR scans were reviewed retrospectively and 2 independent observers performed the measurements. Images were reviewed for (a) assessibility of defect size and septal margins by TOE, and (b) assessibility of defect size and septal margins by CMR, (c) Agreement of the measurements between TOE and CMR. The maximal diameters of the atrial septal defects were measured on both TOE and CMR. Atrial septal margins were measured as previously published $[11,12]$. The anterior inferior (AI) rim was measured from the defect to the mitral valve, the anterior superior (AS) rim from the defect to the aortic root, posterior inferior (PI) rim from the defect to the inferior vena cava and posterior superior (PS) rim from the defect to the superior vena cava (see Figure 1).

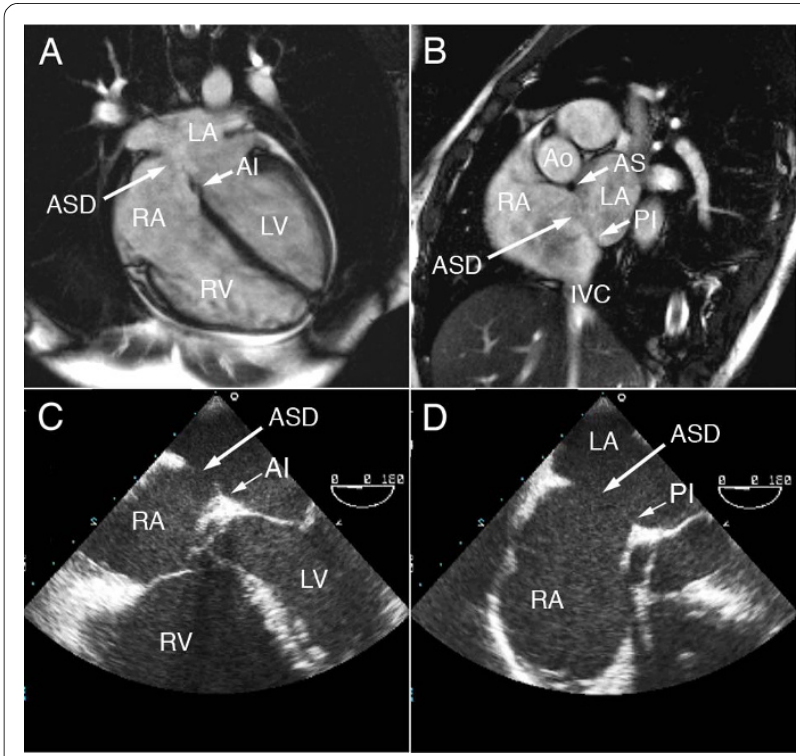

Figure 1 Atrial septal defect (ASD) and margins imaged with CMR (panel A - 4 chamber view, panel B - modified biatrial short axis view) and transoesophageal echocardiography (panel C - 4 chamber view, panel D - biatrial short axis view). Margins are denoted with AS anterior superior rim, Al anterior inferior, PS posterior superior, PI posterior inferior. 
The TOE views for measurement of the rims were: the mid-oesophageal four-chamber view for AI rim, basal short axis view for AS rim and biatrial views for PI and PS rims. Corresponding CMR views were the four-chamber view for AI rim, short axis view through the aorta for the AS rim and modified biatrial short axis views for PS and PI measurements. The size of the device occluder device used was also compared to the maximal defect size on CMR and TOE in patients who subsequently underwent ASD closure.

\section{ASD device implantation}

All implantation of the ASD devices with the Amplatzer Septal occluder were performed with TOE guidance and fluoroscopy. A sizing balloon was used to determine the stretched diameter of the ASD before selection and deployment of ASO device, as previously described [8]. In brief, a Meditech balloon (Boston Scientific, Watertown, MA) sized 20 or $27 \mathrm{~mm}$ was used in this series. This balloon was inflated within the left atrium and firm continuous pressure applied to pull it into the atrial septum, using TOE guidance. The diameter at which the balloon just gets through the atrial septal defect was the stretched balloon diameter (SBD).

\section{Statistical Analysis}

Data is presented as mean \pm standard deviation. Analyses between TOE and CMR were made using simple linear regression analysis (SPSS 11.0 software) and Bland Altman analysis [13]. Statistical significance was taken at a p value of 0.05 .

\section{Results}

A total of 20 patients (M: F $=5: 15$, mean age 42.8 years \pm 15.7) were included in the analyses. All but 1 patient had both TOE and CMR to evaluate their suitability for percutaneous ASD closure. TOE was not performed in 1 patient due to history of an oesophageal stricture. CMR was well tolerated in all patients. Total CMR examination time was 20 to 30 minutes in all cases. Three patients were found not to be suitable for percutaneous ASD closure due to excessive stretched balloon diameter (SBD) of $>40 \mathrm{~mm}$ at cardiac catheterisation (CMR diameters preballoon sizing were 32,38 and $33 \mathrm{~mm}$ ). All 3 patients went on to surgical closure.

\section{Assessibility of defect and margins with TOE}

The maximal defect size could be assessed in all patients $(\mathrm{n}=19)$ with TOE. The anterior inferior (AI) margin, which was measured from the defect to the mitral valve in the mid-oesophageal 4-chamber view could be assessed in all patients. The anterior superior margin was assessable in $79 \%$, the posterior inferior margin in $63 \%$ and the posterior superior margin in $74 \%$ of patients (See Table 1).

\section{Assessibility of defect and margins with CMR}

The maximal defect size could be assessed in all patients $(\mathrm{n}=20)$ with CMR. The anterior inferior, anterior superior and posterior inferior margins could be assessed in all patients. The posterior superior margin could not be assessed in only one patient.

\section{Agreement between TOE and CMR}

There was a good agreement between CMR and TOE for estimation of maximum defect size $(R=0.87)$ and minimum defect size (0.92). There was similar agreement between CMR and TOE versus size of the ASO device (Maximum defect size by CMR vs. ASO size, $\mathrm{R}=0.53$ and maximum defect size by TOE vs. ASO size $R=0.57$ ). See Table 2.

Bland and Altman analyses comparing CMR and TOE measurements of defect size and atrial septal margins are shown in Figures $2 \mathrm{~A}$ to $\mathrm{E}$ and are presented as mean of the 2 measurements obtained by CMR and TOE \pm difference between the 2 measurements.

\section{Discussion}

Many adults with secundum atrial septal defects are now able to have these defects closed percutaneously. The size, location and margins of an atrial septal defect are major determining factors for transcatheter closure. Conventional assessment pre-closure have been with transoesophageal echocardiography (TOE) for measurement of ASD dimensions and margins[7,10]. Inclusion criteria for closure have included ASD maximum diameter of $40 \mathrm{~mm}$ and rims of at least $5 \mathrm{~mm}$ towards the IVC, SVC, right upper pulmonary vein and mitral valve $[8,9]$. However, more recently, deficiency of the margins has still allowed closure. For example, in patients with a deficient anterior superior (AS) margin, a correctly sized Amplatzer septal occluder can successfully be used with the device moulding itself around the aortic wall with minimal risk of perforation $[8,9]$. There have also been small numbers of patients with small inferior and posterior defect margins ( $<5 \mathrm{~mm}$ ) who have been successfully closed [9].

While TOE has been the traditional method for the evaluation and screening for patients who are candidates for transcatheter closure, it is semi-invasive and cannot easily be performed in young children and some adults. Measurements of the ASD can only be obtained from the 4-chamber, short axis and bicaval views on TOE due to the plane on TOE that generally projects the ASD in a relatively fixed direction [11]. In addition, TOE may underestimate the size of the stretched balloon diameter of the ASD, although this has been described to factors associated with choice of plane for maximal diameter in defects that are oval rather than circular in shape, displacement of the interatrial septum from enlarged right atrium and changes of the shape of the defect during the cardiac 
Table 1: Assessment of atrial septal defect size and margins (CMR vs. TOE)

\begin{tabular}{lcc}
\hline & Able to be assessed by CMR (\%) & Able to be assessed by TOE (\%) \\
\hline Maximal defect size & $(20 / 20) 100 \%$ & $(19 / 19) 100 \%$ \\
Anterior superior margin & $(20 / 20) 100 \%$ & $(15 / 19) 79 \%$ \\
Anterior inferior margin & $(20 / 20) 100 \%$ & $(17 / 19) 89 \%$ \\
Posterior superior margin & $(19 / 20) 95 \%$ & $(14 / 19) 74 \%$ \\
Posterior inferior margin & $(20 / 20) 100 \%$ & $(12 / 19) 63 \%$ \\
\hline
\end{tabular}

cycle $[7,14]$. Three-dimensional echocardiography obtained from TOE images may provide superior anatomic detail $[10,15]$, but the accuracy of the reconstructed images is dependent on technical experience of the operator [8].

CMR has been shown to visualise secundum ASDs [16]. Studies comparing CMR with TOE to assess ASD and suitability for percutaneous closure have mainly been done in paediatric populations [11], although there are a limited number of studies with adult patients [17-19]

In this study, we were able to assess maximal atrial defect size in all patients with both TOE and CMR. In the assessment of atrial septal margins, CMR could assess the posterior inferior margins in all patients compared to approximately $60 \%$ that could be assessed with TOE. One study in a paediatric population comparing TOE and MRI assessment showed that patients who had successful closure had a significantly smaller major axis of ASD and larger posterior inferior rim compared to those who were excluded from closure procedure. An adequate posterior inferior rim was also best visualised in that study with CMR and showed a better correlation of ASD diameter measurement to balloon sizing compared to TOE [11]. However, a limitation in our study of the measurement of margins using TOE relates to this study being a retrospective study and with the images that were strictly required for measurement of the margins (such as the PI margin) not being available in some patients. Hence the $60 \%$ assessibility for the PI margin is not a true reflection of the ability of TOE to define this margin.

In the patients $(n=3)$ that went on to surgical closure of their defects, although the pre-procedure ASD diameters on CMR were less than $40 \mathrm{~mm}$ (between $32-38 \mathrm{~mm}$ in fact), the stretched balloon diameters were $>40 \mathrm{~mm}$, which is beyond the largest ASD amplatzer closure devices available, at the time of invasive assessment.

Table 2: Maximal ASD diameters and Amplatzer septal occluder size

\begin{tabular}{|c|c|c|c|}
\hline Patient & Maximal MRI Diameter (mm) & $\begin{array}{l}\text { Maximal TOE Diameter } \\
(\mathbf{m m})\end{array}$ & ASO Size (mm) \\
\hline 1 & 19.7 & 16 & 26 \\
\hline 2 & 11.8 & 11 & 18 \\
\hline 3 & 25.2 & 21 & 32 \\
\hline 4 & 17.9 & 21 & 32 \\
\hline 5 & 19.1 & 23 & 20 \\
\hline 6 & 15.1 & 14 & 18 \\
\hline 7 & 12.7 & 14 & 24 \\
\hline 8 & 25.9 & 35 & 38 \\
\hline 9 & 19.2 & 18 & 26 \\
\hline 10 & 15.7 & 12 & 20 \\
\hline 11 & 11.4 & 10 & 16 \\
\hline 12 & 15.9 & 19 & 30 \\
\hline 13 & 20 & 21 & 26 \\
\hline 14 & 24.2 & Not Performed & 30 \\
\hline 15 & 23.6 & 22 & 28 \\
\hline 16 & 25 & 27 & 28 \\
\hline 17 & 9.2 & 10 & 20 \\
\hline
\end{tabular}




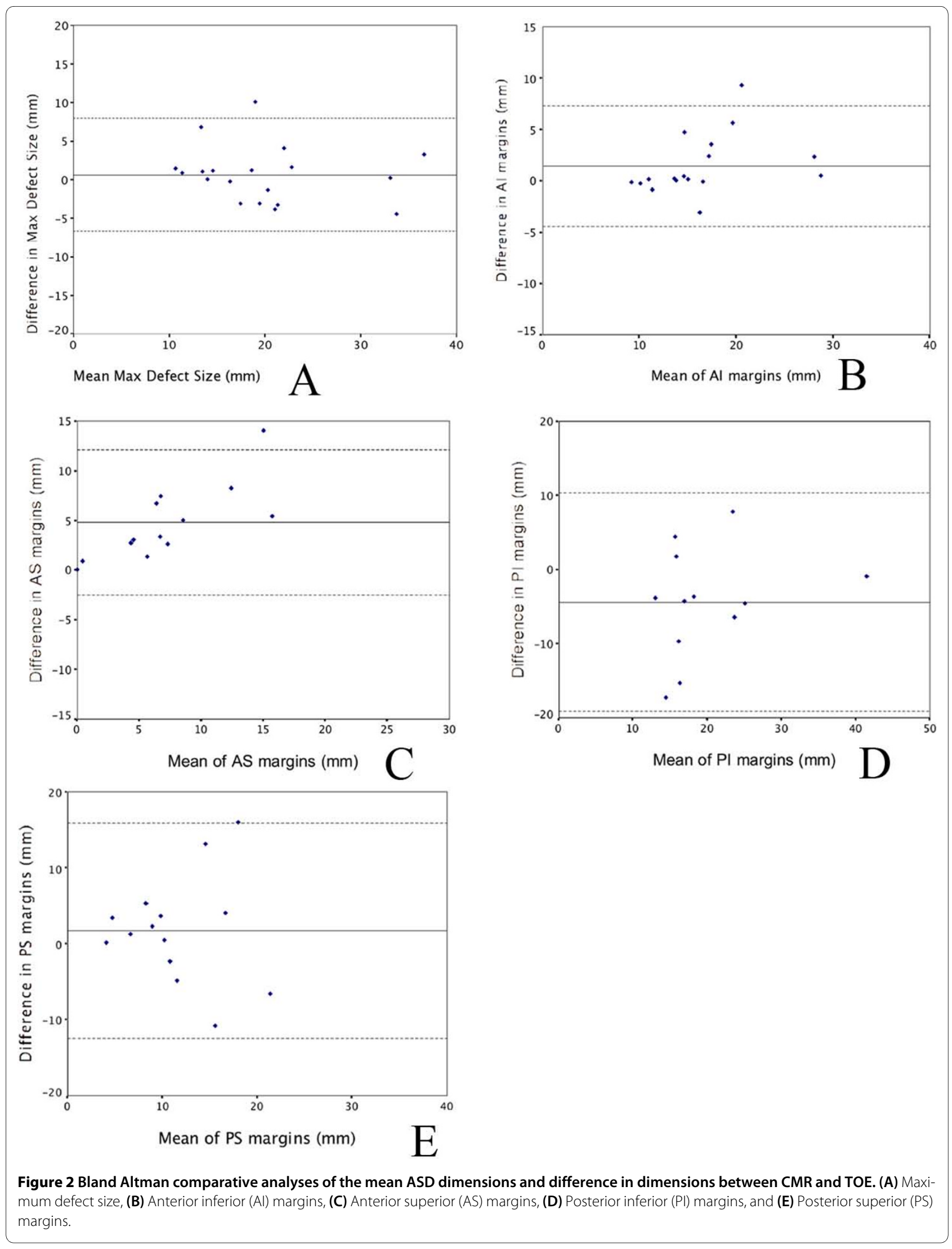


Velocity encoded contrast cine imaging was not performed in this study, however, this is another CMR technique that can provide information about the size and shape of the atrial septal defect $[16,18]$ as well as provide accurate assessment of shunt magnitude from measuring flow in the systemic and pulmonary circulations [20,21]. However, this technique has not been used for the assessment of margins due to its limited spatial resolution.

\section{Conclusions}

CMR agrees closely with TOE assessment of atrial septal defects for percutaneous closure. In addition, it is able to assess the septal margins such as the posterior inferior margin, which is known to be difficult to assess with TOE. Potentially, CMR could be used instead of TOE for the assessment for percutaneous closure.

\section{Competing interests}

The authors declare that they have no competing interests.

\section{Authors' contributions}

KSLT participated in the study design, CMR data acquisition, analysis and manuscript preparation. PJD and BKD participated in TOE data analysis and manuscript revision. MAB, MIW and PS contributed to manuscript revision. SGW conceived the study and revised the manuscript. All authors read and approved the final manuscript.

\section{Author Details}

Cardiovascular Research Centre, Royal Adelaide Hospital and The University of Adelaide, Adelaide, South Australia

Received: 6 April 2010 Accepted: 22 July 2010

Published: 22 July 2010

\section{References}

1. Hoffman JI, Kaplan S, Liberthson RR: Prevalence of congenital heart disease. Am Heart J 2004, 147:425-439.

2. Roos-Hesselink JW, Meijboom FJ, Spitaels SE, van Domburg R, van Rijen EH, Utens EM, Bogers AJ, Simoons ML: Excellent survival and low incidence of arrhythmias, stroke and heart failure long-term after surgical ASD closure at young age. A prospective follow-up study of 21-33 years. Eur Heart J 2003, 24:190-197.

3. Galal MO, Wobst A, Halees Z, Hatle L, Schmaltz AA, Khougeer F, De Vol E, Fawzy ME, Abbag F, Fadley F, et al:: Peri-operative complications following surgical closure of atrial septal defect type II in 232 patients-a baseline study. Eur Heart J 1994, 15:1381-1384.

4. Du ZD, Hijazi ZM, Kleinman CS, Silverman NH, Larntz K: Comparison between transcatheter and surgical closure of secundum atrial septal defect in children and adults: results of a multicenter nonrandomized trial. J Am Coll Cardiol 2002, 39:1836-1844.

5. Chan KC, Godman MJ, Walsh K, Wilson N, Redington A, Gibbs JL: Transcatheter closure of atrial septal defect and interatrial communications with a new self expanding nitinol double disc device (Amplatzer septal occluder): multicentre UK experience. Heart 1999, 82:300-306.

6. Lopez K, Dalvi BV, Balzer D, Bass JL, Momenah T, Cao QL, Hijazi ZM Transcatheter closure of large secundum atrial septal defects using the $40 \mathrm{~mm}$ Amplatzer septal occluder: Results of an international registry. Catheter Cardiovasc Interv 2005

7. Cooke JC, Gelman JS, Harper RW: Echocardiologists' role in the deployment of the Amplatzer atrial septal occluder device in adults. J Am Soc Echocardiogr 2001, 14:588-594.

8. Harper RW, Mottram PM, McGaw DJ: Closure of secundum atrial septal defects with the Amplatzer septal occluder device: techniques and problems. Catheter Cardiovasc Interv 2002, 57:508-524.
9. Du ZD, Cao QL, Rhodes J, Heitschmidt M, Hijazi ZM: Choice of device size and results of transcatheter closure of atrial septal defect using the amplatzer septal occluder. J Interv Cardiol 2002, 15:287-292.

10. Cao Q, Radtke W, Berger F, Zhu W, Hijazi ZM: Transcatheter closure of multiple atrial septal defects. Initial results and value of two- and three-dimensional transoesophageal echocardiography. Eur Heart $J$ 2000, 21:941-947.

11. Durongpisitkul K, Tang NL, Soongswang J, Laohaprasitiporn D, Nanal A: Predictors of successful transcatheter closure of atrial septal defect by cardiac magnetic resonance imaging. Pediatr Cardiol 2004, 25:124-130.

12. Masani ND: Transoesophageal echocardiography in adult congenital heart disease. Heart 2001, 86(Suppl 2):|130-1140.

13. Bland JM, Altman DG: Statistical methods for assessing agreement between two methods of clinical measurement. Lancet 1986, 1:307-310.

14. Fischer G, Kramer HH, Stieh J, Harding P, Jung O: Transcatheter closure of secundum atrial septal defects with the new self-centering Amplatzer Septal Occluder. Eur Heart J 1999, 20:541-549.

15. Zhu W, Cao QL, Rhodes J, Hijazi ZM: Measurement of atrial septal defect size: a comparative study between three-dimensional transesophageal echocardiography and the standard balloon sizing methods. Pediatr Cardiol 2000, 21:465-469.

16. Holmvang G, Palacios IF, Vlahakes GJ, Dinsmore RE, Miller SW, Liberthson RR, Block PC, Ballen B, Brady TJ, Kantor HL: Imaging and sizing of atrial septal defects by magnetic resonance. Circulation 1995, 92:3473-3480

17. Weber C, Weber M, Ekinci O, Neumann T, Deetjen A, Rolf A, Adam G, Hamm CW, Dill T: Atrial septal defects type II: noninvasive evaluation of patients before implantation of an Amplatzer Septal Occluder and on follow-up by magnetic resonance imaging compared with TEE and invasive measurement. Eur Radiol 2008, 18:2406-2413.

18. Thomson LE, Crowley AL, Heitner JF, Cawley PJ, Weinsaft JW, Kim HW, Parker M, Judd RM, Harrison JK, Kim RJ: Direct en face imaging of secundum atrial septal defects by velocity-encoded cardiovascular magnetic resonance in patients evaluated for possible transcatheter closure. Circ Cardiovasc Imaging 2008, 1:31-40.

19. Piaw CS, Kiam OT, Rapaee A, Khoon LC, Bang LH, Ling CW, Samion H, Hian SK: Use of non-invasive phase contrast magnetic resonance imaging for estimation of atrial septal defect size and morphology: a comparison with transesophageal echo. Cardiovasc Intervent Radiol 2006, 29:230-234.

20. Brenner LD, Caputo GR, Mostbeck G, Steiman D, Dulce M, Cheitlin MD, O'Sullivan M, Higgins CB: Quantification of left to right atrial shunts with velocity-encoded cine nuclear magnetic resonance imaging. J Am Coll Cardiol 1992, 20:1246-1250.

21. Hundley WG, Li HF, Lange RA, Pfeifer DP, Meshack BM, Willard JE, Landau C, Willett D, Hillis LD, Peshock RM: Assessment of left-to-right intracardiac shunting by velocity-encoded, phase-difference magnetic resonance imaging. A comparison with oximetric and indicator dilution techniques. Circulation 1995, 91:2955-2960.

doi: $10.1186 / 1532-429 X-12-44$

Cite this article as: Teo et al., Assessment of atrial septal defects in adults comparing cardiovascular magnetic resonance with transoesophageal echocardiography Journal of Cardiovascular Magnetic Resonance 2010, 12:44 